\title{
The Determination of Dopamine in the Presence of Ascorbic Acid at the Modified Glassy Carbon Electrode with Phytic Acid and Single-Walled Carbon Nanotubes
}

\author{
Si Ra Bae, Haesang Jeong, Suhee Jo, and Seungwon Jeon ${ }^{*}$ \\ Department of Chemistry and Institute of Basic Science, Chonnam National University, Gwangiu 500-757, Korea \\ "E-mail: swieon@chommam.ac.kr. \\ Received Mav 25, 2007
}

\begin{abstract}
$\Lambda$ glassy carbon electrode (GCE) modified with phytic acid (P $\Lambda$ ) and single-walled carbon nanotubes (SWNTs) were investigated by voltammetric methods in buffer solution. The P $\Lambda$-SWNTs/GCE-modified electrode demonstrated substantial enhancements in electrochemical sensitivity and selectivity towards dopamine (D $\Lambda$ ) in the presence of $L$-ascorbic acid $(\Lambda \Lambda)$. The $\mathrm{P} \Lambda$-SWNTs films promoted the electron transfer reaction of $\mathrm{D} \Lambda$, while the $\mathrm{P} \Lambda$ film, acting as a negatively charged linker, combined with the positively charged $\mathrm{D} \Lambda$ to induced $\mathrm{D} \Lambda$ accumulation in the film at $\mathrm{pII}$ under 7.4. Ilowever, the $\mathrm{P} \Lambda$ film restrained the electrochemical response of the negatively charged $\Lambda \Lambda$ due to the electrostatic repulsion. The anodic peak potentials of $\mathrm{D} \Lambda$ and $\Lambda \Lambda$ could be separated by electrochemical techniques, and the interferences from $\Lambda \Lambda$ were effectively eliminated in the $\mathrm{D} \Lambda$ determination. Linear calibration plots were obtained in the $\mathrm{D} \Lambda$ concentration range of 0.1-10 $\mu \mathrm{M}$ and the detection limit of the $\mathrm{D} \Lambda$ oxidation current was determined to be $0.06 \mathrm{lM}$ at a signal-to-noise ratio of 3 . The results indicated that the modified electrode is used to determine $\mathrm{D} \Lambda$ without interference from $\Lambda \Lambda$.
\end{abstract}

Key Words : Single-walled carbon nanotubes, Phytic acid, Glassy carbon electrode, Dopamine, Electrocatalytic oxidation

\section{Introduction}

Significant efforts have been made for the application of CNTs due to their excellent biocompatibility and electron transfer ability after the discoveryl of carbon nanotubes (CNTs). Recently CNTs have been intensively employed as modification materials on the surface of carbon fiber, ${ }^{2,3}$ gold ${ }^{4.7}$ platinum ${ }^{8.9}$ graphite, ${ }^{10.11}$ and glassy carbon electrodes. ${ }^{12-16}$ Their modified electrodes, with supporting molecules as a binder or ion-exchanger, have been applied to the determination of many biomolecules, such as DA, ${ }^{1724}$ Serotonin (5-hydroxytryptamine, or 5-HT), ${ }^{25,26}$ hydrogen peroxide, ${ }^{27.28}$ amino acids, ${ }^{29}$ glucose, ${ }^{30-32}$ dihydronicotinamide adenine dinucleotide (NADH), ${ }^{33-35}$ and heavy metals. ${ }^{36}$

Phytic acid (PA), a naturally derived material from legume seeds, cereal grains, and beans, is biocompatible, nontoxic, and green to the environmental and biological applications. The structure of PA has 12 acid groups attached symmetrically to a cyclohexanehexol ring. The six protons among them are strongly acidic with approximate $\mathrm{p} K_{\mathrm{a}}$ values below 3.5 , and the remaining six are very weakly acidic with $\mathrm{p} K_{\mathrm{a}}$ values between 4.6 and $10 .^{37}$ Therefore, PA is usually a negatively charged molecule over $\mathrm{pH}>1.5$, and has a strong tendency to interact with positively charged metal ions ${ }^{38-40}$ or proteins ${ }^{41}$ due to its unique structure and property. A large negative charge on a PA molecule under the appropriate conditions renders PA a good candidate as a polydentate binder or a negatively charged linker molecule. Assembled layer-by-layer films of PA with inorganic nanoparticles such as $\mathrm{TiO}_{2}{ }^{41-44} \mathrm{Fe}_{2} \mathrm{O}_{3}{ }^{45}$ and $\mathrm{Fe}_{3} \mathrm{O}_{4}$-chitosan ${ }^{46}$ were reported, and the direct electrochemistry of cytochrome $c{ }^{43}$ hemo- globin, ${ }^{46}$ and proteins ${ }^{41}$ absorbed into these films has also been investigated. In this study, a PA-SWNTs/GCE-modified electrode was prepared with single-walled CNTs (SWNTs) and PA as a binder and a charge linker on the bare glassy carbon electrode. The modified electrode was studied for the DA voltammetric response in the presence of AA. The PA-SWNTs/GCE-modified electrode accumulated DA into the film by ion-pairing process, and largely improved the DA electrochemical response. The oxidative potentials of DA and AA could be separated by the modified electrode, thereby enabling the independent determination of DA in the presence of AA.

\section{Experimental}

Chemicals and electrochemical apparatus. SWNTs $(1.2-1.5 \mathrm{~nm}$ in diameter produced by arc method) purchased from Aldrich were purified with $6.0 \mathrm{M} \mathrm{HCl}$ solution. PA, $\mathrm{DA}$, and AA were also purchased from Aldrich. All other reagents used were of analytical grade. The $\mathrm{pH}$ of the phosphate buffer saline (PBS) solution was adjusted with 0.1 $\mathrm{M} \mathrm{H}_{3} \mathrm{PO}_{4}$ and $0.1 \mathrm{M} \mathrm{NaOH}$. High purity argon was used for deaeration. All experiments were carried out at room temper-zature. Doubly distilled water with resistibility over $18 \mathrm{M} \Omega \mathrm{cm}$ in a quartz apparatus was used to prepare all aqueous electrolyte solutions.

Cyclic voltammetry (CV) and differential pulse voltammetry (DPV) were performed with a three-electrode potentiostat [Bioanalytical Systems (BAS) $100 \mathrm{~B} / \mathrm{W}$ ] in a ground Faraday cage. DPV conditions were $20 \mathrm{mV} / \mathrm{s}$ scan rate, 50 $\mathrm{mV}$ pulse amplitude, and $50 \mathrm{msec}$ pulse width for DA 
<smiles>O=POC1C(O)[C@H](OP)[C@@H](OP)[C@@H](OP)[C@@H]1OP</smiles>

Figure 1. Structure of the phytic acid (PA).

determination in the presence of AA. A platinum-wire electrode was used as an auxiliary electrode. $\mathrm{A} \mathrm{Ag} / \mathrm{AgCl}$ electrode supplied by BAS was used as the reference electrode. The PA-SWNTs/GCE-modified electrode was used as the working electrode. GCE ( $3 \mathrm{~mm}$ in diameter) was purchased from BAS. All potentials were reported with respect to the $\mathrm{Ag} / \mathrm{AgCl}$ electrode at room temperature under argon atmosphere. The $\mathrm{pH}$ measurements were performed by $\mathrm{pH}$ glass electrode with a JENCO meter.

Preparation of the PA-SWNTs/GCE-modified electrode. Ultrasonic agitation for $30 \mathrm{~min}$ was used to disperse I $\mathrm{mg}$ SWNTs and $1 \%$ PA (10 $\mathrm{mg}$ ) into $1 \mathrm{~mL}$ of water to make a black and homogeneous suspension. The GCE surface was highly polished with alumina paste, sonicated with ultrasonic agitation for $5 \mathrm{~min}$, washed with $1.0 \mathrm{M} \mathrm{HCl}$ solution, and then rinsed with distilled water several times and methanol finally. After being cleaned thoroughly, the GCE surface was heated with an IR lamp, and then the heated GCE was coated with 5 HL of the black suspension containing PA and SWNTs. The water was evaporated in the air at room temperature, and the coated GCE was dried under the IR lamp to produce the PA-SWNTs/GCE-modified electrode. The modified electrode was activated in 0.1 M PBS solution at $\mathrm{pH} 7.4$ by successive cyclic scans between -0.6 and $+0.8 \mathrm{~V}$. Before and after each experiment, the modified electrode was washed with distilled water and reactivated by the method mentioned described above. All experiments were carried out in a $15 \mathrm{~mL}$ electrolytic cell with $5 \mathrm{~mL}$ PBS solutions, where dioxygen was removed by purging with high-purity argon for experiments continuously.

\section{Results and Discussion}

Surface morphology of the PA-SWNTs/GCE-modified electrode. The SEM image of the surface of the PA-SWNTs/ GCE film electrode clearly shows the existence of SWNTs in bundles with diameters of $15-25 \mathrm{~nm}$, and some of the bundles twisted together, shown in Figure $2{ }^{+7}$ The length of the SWNT bundle was immeasurable as both ends of the bundle were not shown simultaneously. The image illustrates the uniform dispersion of SWNTs on the electrode, and the possible absorption of PA on the wall of the SWNT bundles.

Electrochemical response of dopamine at the PA-SWNTs/ GCE-modified electrode. The DA cyclic voltammograms (CVs) at the bare GCE, SWNTs/GCE, and PA-SWNTs/ GCE-modified electrodes in the PBS solution at $\mathrm{pH} 7.4$ were shown Figure 3. Figure 3a shows the voltammetric response of $10 \mu \mathrm{M} \mathrm{DA}$ at the bare GCE. A small anodic peak DA

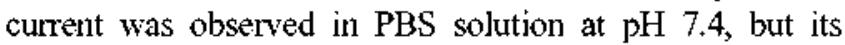

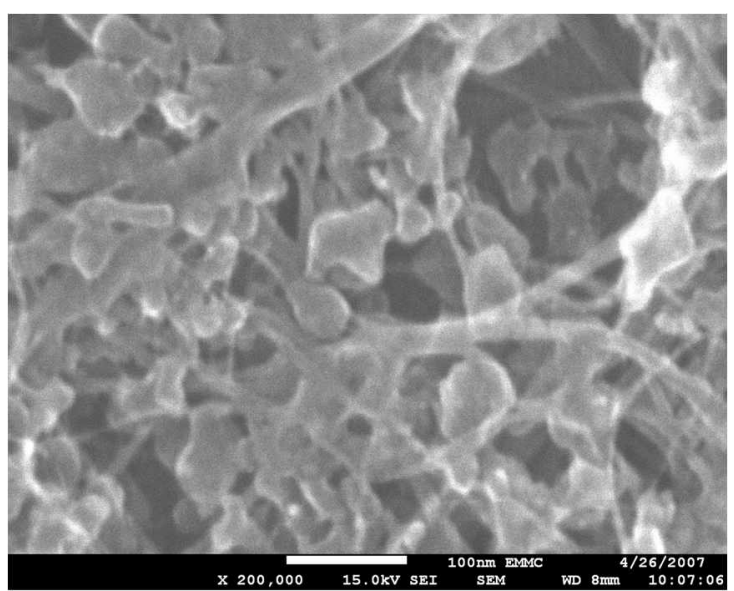

Figure 2. SEM inage of the PA-SWNTs film on a glassy carbon electrode.
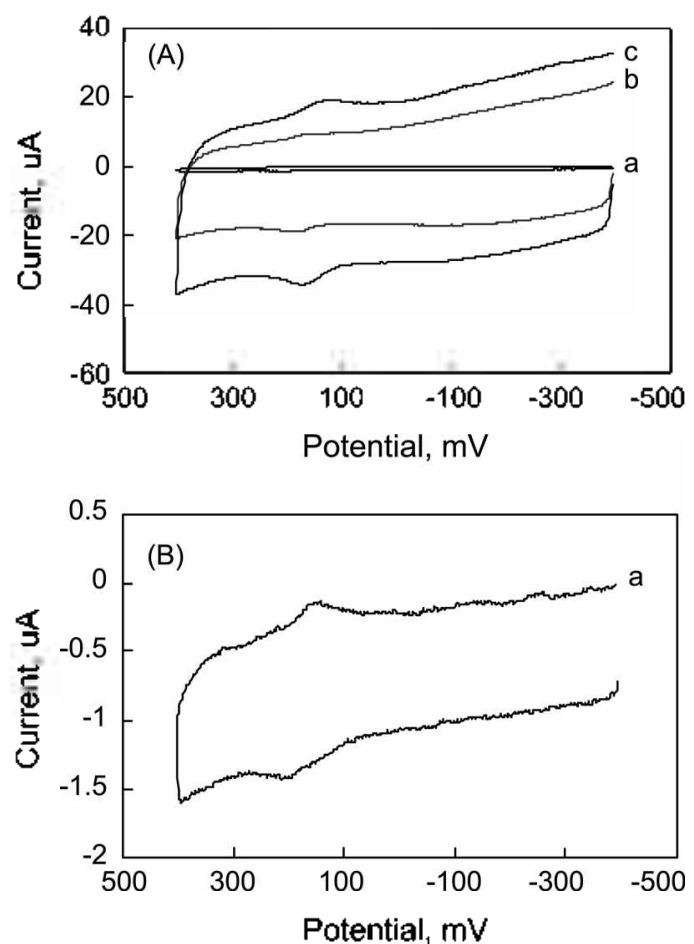

Figure 3. Cyclic voltanmograms for the clectrochemical responsc of $10 \mu \mathrm{M}$ DA at a bare GCE (a), SWNTs/GCE-modified electrode (b), and PA-SWNTs/GCE-modified electrode (c) in PBS solutions at $\mathrm{pH} 7.4$ with a scan rate of $100 \mathrm{mV} / \mathrm{s}$.

background current was low. There were no voltammetric responses on the PA-SWNTs/GCE-modified electrode in the blank PBS solution, nor on the bare GCE at the same potential range (not shown). CVs of $10 \mu \mathrm{M}$ DA at the PASWNTS/GCE-modified electrode in PBS solution at $\mathrm{pH} 7.4$ are given in Figure $3 \mathrm{c}$. The DA anodic potential $(0.174 \mathrm{~V})$ at the modified electrode was slightly shifted to negative direction when compared with that at the bare GCE $(0.212$ $\mathrm{V}$ ), and the DA oxidative current at the modified electrode was largely increased relative to that at the bare $\mathrm{GCE}$, indicating the DA electrocatalytic ability of the modified electrode. The electrocatalytic effect was attributed to the 
larger available surface area of the modified electrode due to the nanometer dimensions of the nanotubes, the excellent electrical characteristics of the PA-SWNTs film electrode, and the strong combination tendency PA to DA by electrostatic interaction. To prove the enhancement effect of PASWNTs for DA oxidation, a comparison experiment was also performed at the pure PA-modified GCE, with no increase in the peak DA currents being observed. Stripping voltammograms at a concentration of $10 \mu \mathrm{M} \mathrm{DA}$ further confirmed the strong combination tendency of PA to DA and the DA adsorption to SWNTs on the PA-SWNTs/GCEmodified electrode surface. The accumulation time had little effect on the DA oxidation peak currents at the bare GCE, but these currents increased significantly with increasing accumulation time at the PA-SWNTs/GCE-modified electrode.

The effect of scan rate $(0.025-0.625 \mathrm{~V} / \mathrm{sec})$ on DA oxidation at the modified electrode by $\mathrm{CV}$ was investigated in PBS solution at pH 7.4. The anodic peak current of the modified electrode in the DA solution increased linearly with increasing scan rate, indicating that direct electron transfer between DA and the modified electrode occurred on the modified electrode surface. The first cathodic peak current also increased linearly with increasing scan rate. The linearity of the plots was very reasonable, with correlation coefficients of 0.999 on the anodic current and 0.987 on the cathodic current, as shown in Figure 4. Therefore, the electrode DA reaction at the modified electrode seems to have been an adsorption-controlled process.

The amount of SWNTs on the GCE surface is related to the thickness of the cast film and the total specific surface area, and therefore influences the DA adsorption on the electrode surface. The anodic peak DA current may be dependent on the amount of SWNTs on the GCE. The relationship between the amount of SWNTs on the GCE and the DA oxidation peak current was examined by the

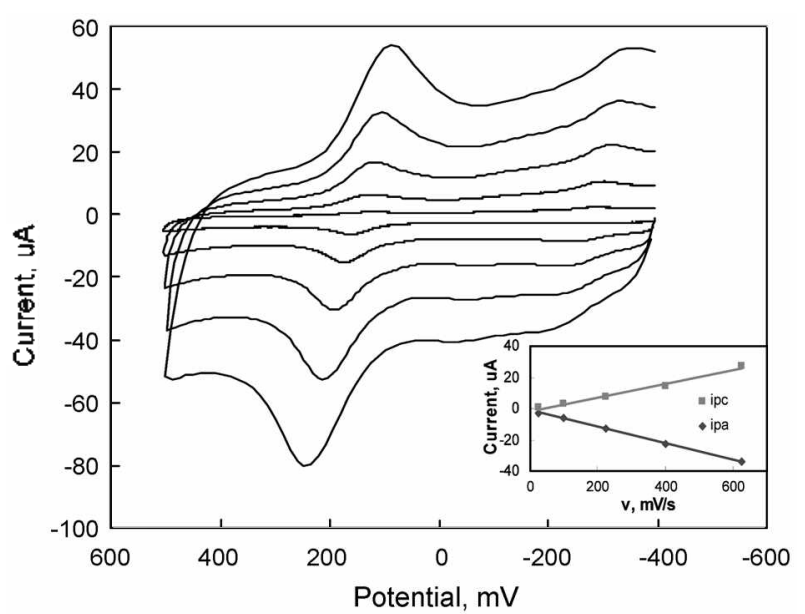

Figure 4. Cyclic voltammograms obtained at different scan rates from the PA-SWNTS/GCE-modified electrode in PBS solution at $\mathrm{pH} 7.4$ containing $10 \mu \mathrm{M} \mathrm{D \Lambda}$. Scan rates: $0.025-0.625 \mathrm{~V} / \mathrm{s}$. Inset: plots of anodic and cathodic peak currents as a function of scan rate. controlled volume ( $7 \mu \mathrm{L}$ ) of the solution of $1 \mathrm{mg}$ SWNTs and $1 \% \mathrm{PA}$ in $1 \mathrm{~mL}$ water. At first, the oxidation peak current increased gradually with increasing volume of the dispersion solution over the electrode surface because of the increased DA adsorptions on the electrode surface. When the volume of the dispersion solution exceeded $7 \mu \mathrm{L}$, no obvious changes in the peak currents were observed, suggesting that the increased film thickness no longer affected the DA adsorption and that the electron transfer processes within the PA-SWNTs film were sufficiently rapid. However, the charging current was also increased with increasing amount of SWNTs on the electrode surface, and thereby obstructed the DA determination at low concentration levels. Therefore, the optimal volume of $7 \mu \mathrm{L}$ was chosen in the next experiments.

The $\mathrm{pH}$ of the supporting electrolyte has a significant influence on the DA electrooxidation at the PA-SWNTs film-modified electrode by affecting both peak current and peak potential. Figure $5 \mathrm{~A}$ shows CVs of $50 \mathrm{mM}$ DA in the different $\mathrm{pH}$ solutions, and Figure $5 \mathrm{~B}$ illustrates the dependences of the DA anodic peak current and redox potential on the buffer solution $\mathrm{pH}$. The anodic peak current increased with increasing solution $\mathrm{pH}$, while the DA peak current peaked at $\mathrm{pH} 7.4$. Because the physiological $\mathrm{pH}$ was close to
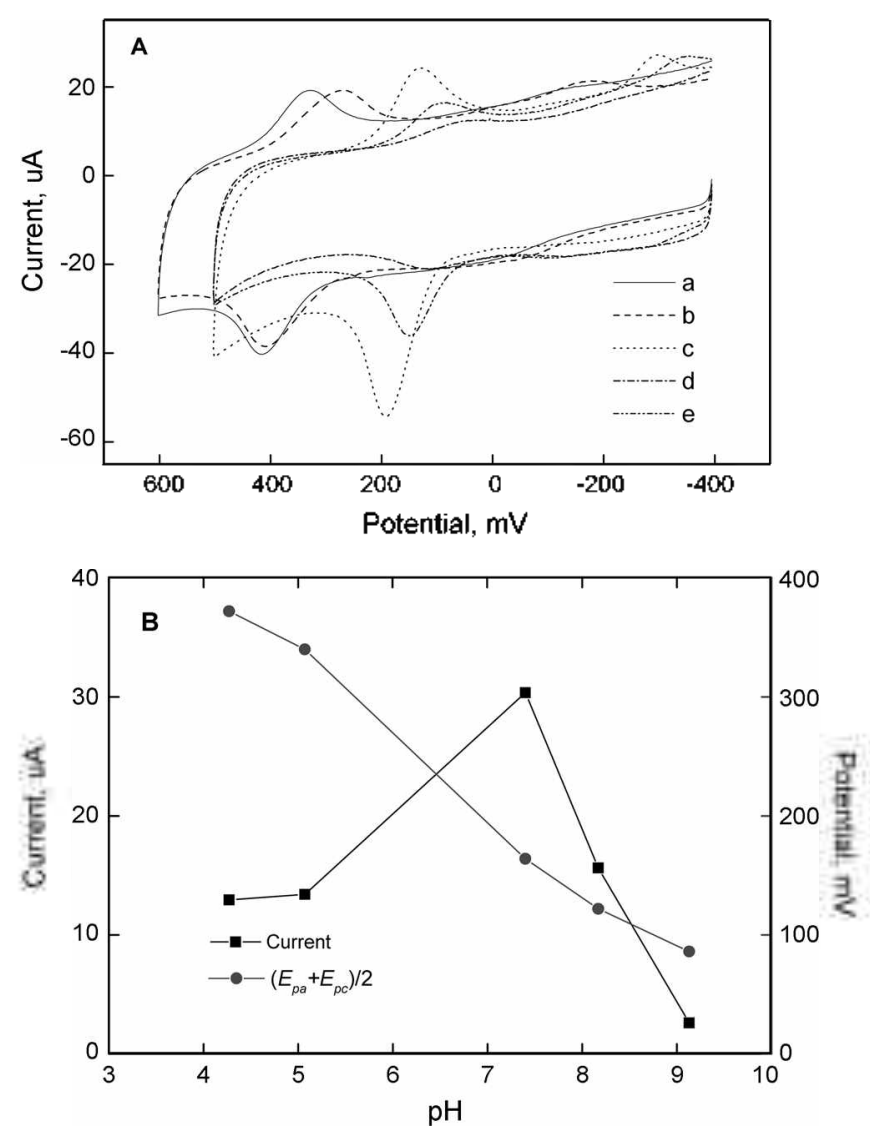

Figure 5. Cyclic voltamınograns of $50 \mu \mathrm{M} \mathrm{DA}$ in different $\mathrm{pH} 4.3$ (a), 5.1 (b), 7.4 (c), 8.2 (d), and 9.1 (e) solutions at the PA-SWNTsi GCE-modified electrode (A), and the dependences of the DA peak current and redox potential on the PBS solution $\mathrm{pH}(\mathrm{B})$ with a scan rate of $100 \mathrm{mV} / \mathrm{s}$. 


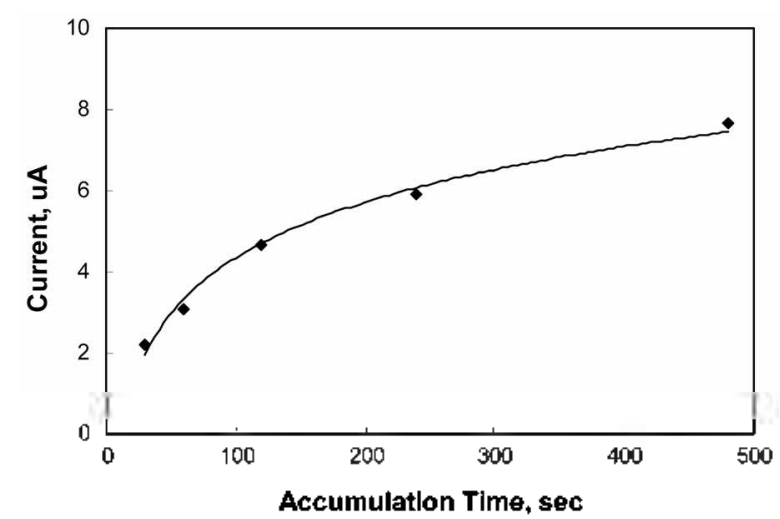

Figure 6. Effect of accumulation times on the peak current of 10 $4 \mathrm{M}$ DA at the PA-SWNTs/GCE-modified electrode in PBS solutions at $\mathrm{pH} 7.4$ with a scan rate of $100 \mathrm{mV} / \mathrm{s}$.

$\mathrm{pH} 7.4$ and the anodic current was higher at $\mathrm{pH} 7.4$, PBS solution at $\mathrm{pH} 7.4$ was chosen for use in all experiments. The effect of $\mathrm{pH}$ on peak DA current may have resulted from its ion-pair with PA and adsorption on the PA-SWNTs/GCEmodified electrode. DA $\left(\mathrm{p} K_{i q}=8.87\right)$ is known to be a catecholamine molecule and can become protonated as cations at lower $\mathrm{pH}$. Meanwhile, $\mathrm{p} K_{t}$ of $\mathrm{PA}$ is below 3 (for six protons) and 4-10 (for other six protons) as mentioned above, so PA may become deprotonated and gain a negative charge with increasing $\mathrm{pH}$. At low $\mathrm{pH}, \mathrm{PA}$ is dominantly protonated and DA is also protonated, and thier electrostatic attraction between DA and PA on the PA-SWNTs/GCEmodified electrode may be weak. At high $\mathrm{pH}, \mathrm{PA}$ is dominantly deprotonated and DA is also deprotonated, and the ionpairing of DA and PA may be inefficient. However, thier electrostatic attraction between DA and PA on the PASWNTs/GCE-modified electrode may be strong around $\mathrm{p} K_{a}$ of DA, and the ion-pairing of DA and PA is efficient. The oxidative potential shifted negatively with increasing $\mathrm{pH}$ due to the participation of protons in the electrode reaction.

The effect of accumulation times on the peak DA current was studied. The peak currents increased very quickly with increasing accumulation time (Fig. 6). This phenomenon demonstrates that rapid ion-pairing of DA with PA on the surface of the PA-SWNTs/GCE-modified electrode was responsible. The peak currents increased rapidly with the accumulation time for the determination of $10 \mu \mathrm{M}$ DA, while the peak DA current on the electrode was not markedly increased with further increase in the accumulation time due to surface saturation. The DA sensitivity at lower concentrations was improved by increasing the accumulation time. Therefore, an accumulation time of $120 \mathrm{sec}$ was chosen to save analysis time in all experiments.

The effect of accumulation potentials on the peak DA current was studied. The peak current increased with increasingly negative accumulation potential up to $-0.4 \mathrm{~V}$, but then remained almost constant (Fig. 7). Therefore, an accumulation potential of $-0.4 \mathrm{~V}$ was chosen in all experiments.

The reproducibility and reusability of PA-SWNTs/GCE-

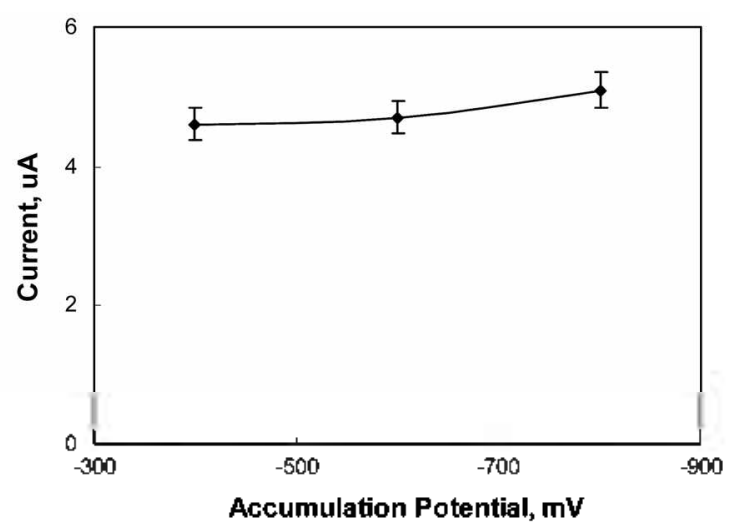

Figure 7. Effect of accuinulation potentials on the peak current of $10 \mu \mathrm{M}$ D $\Lambda$ at the $\mathrm{P} \Lambda$-SWNTS/GCE-modified electrode in PBS solutions at $\mathrm{pH} 7.4$ with a scan rate of $100 \mathrm{mV} / \mathrm{s}$.

modified electrode for DA determination were investigated. Repetitive DA deteminations were carried out in the solution of $10 \mu \mathrm{M} \mathrm{DA}$ in $0.1 \mathrm{M}$ PBS solution at $\mathrm{pH} 7.4$. The $\mathrm{PA}-\mathrm{SWNT} / \mathrm{GCE}$-modified electrode was easily regenerated by potential cycling between $-0.6 \mathrm{~V}$ to $1.0 \mathrm{~V}$ at a scan rate of $100 \mathrm{mV} / \mathrm{s}$ in blank PBS solution. In the cycle of preconcentration, determination, regeneration, and cleaning, the relative standard deviation (RSD) of $3.0 \%$ was obtained for DA for five replicate measurements. This result confinms the good stability and reproducibility for DA determination of the recommended method using the fabricated PASWNTs/GCE-modified electrode.

DA determination in the presence of AA at the modified electrode. The amount of negatively charged polymer in the electrode film should promote the selectivity and sensitivity of DA detection in the presence of interfering molecule. PA can be used as a negatively charged molecule to improve DA determination in the presence of AA. DA deternination in the presence of AA was investigated in order to establish its selectivity. DPV was used to improve the resolution among the voltammograms. In separated experiments, the anodic waves of DA and AA overlap completely, making it very difficult to measure absolutely the DA anodic current in the presence of even a small excess of AA at the bare GC electrode. DPV of AA showed that the oxidative potential was shifted in a negative direction to $-0.07 \mathrm{~V}$ at the modified electrode, and that the anodic peak current was largely decreased when compared with that at the bare GCE.

Figure 8 illustrates a series of DPVs obtained for DA at varying concentrations $(0.0 \mu \mathrm{M}-10 \mu \mathrm{M})$ in the presence of 1 $\mathrm{mM}$ AA at the modified electrode in 0.1 M PBS solution at $\mathrm{pH}$ 7.4. In the absence of DA, DPV of AA presented an anodic oxidative peaks of AA $(-0.07 \mathrm{~V})$, and indicated a small anodic peak current of AA. With the addition of DA to the solution of AA, a new anodic peak appeared, corresponding to DA oxidation. The anodic peak current corresponding to the DA oxidation potential $(0.16 \mathrm{~V})$ was increased with increasing DA concentration in the presence of $\mathrm{AA}$, without the variation of anodic peak currents of AA. 


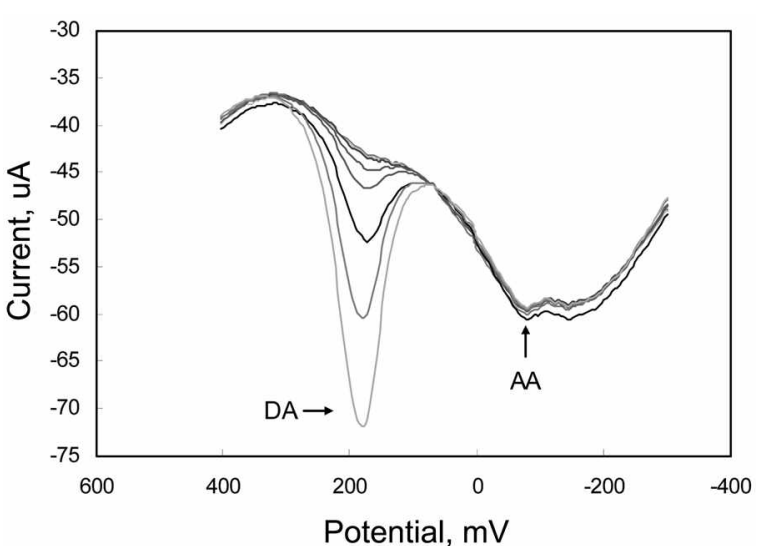

Figure 8. DPVs for $0.0,0.1,0.2,0.5,1.0,2.0,5.0$, and $10 \mu \mathrm{M}$ DA in the presence of $1 \mathrm{mM} \mathrm{AA}$ at the PA-SWNTs/GCE-modified electrode in PBS solution at $\mathrm{pH} 7.4$ with a $20 \mathrm{mV} / \mathrm{s}$ scan rate, 50 $\mathrm{mV}$ pulse amplitude, and $50 \mathrm{msec}$ pulse width.

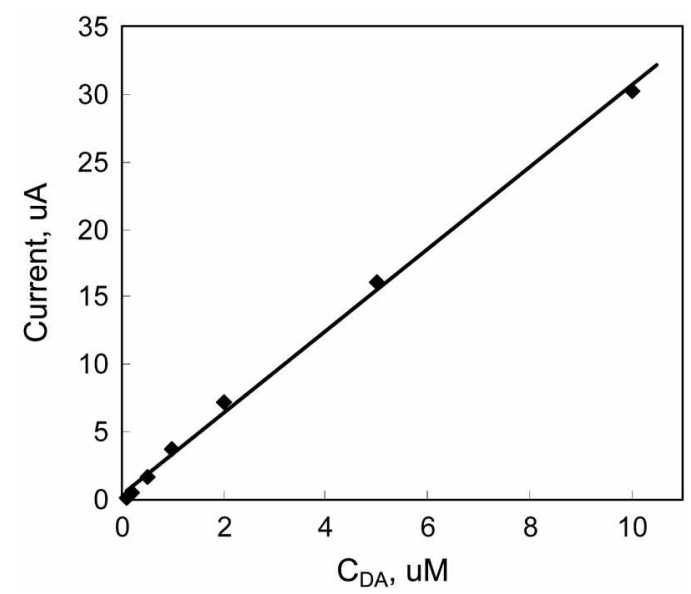

Figure 9. Plots of DA anodic current in the presence of AA as a function of the DA concentration at the PA-SWNTS/GCE-modified clectrode.

The DA anodic current exhibited a linear relationship with DA concentration, even in the presence of $\mathrm{AA}$, with a correlation coefficient of 0.998 in the concentration region studied (Fig. 9). The detection limit was $0.06 \mu \mathrm{M}$ at a signalto-noise ratio of 3 in PBS solution at $\mathrm{pH} 7.4$ to represent a biological $\mathrm{pH}$. The RSD of the same modified electrode in 5 successive scans was about $2.2 \%$ for $10 \mu \mathrm{M} \mathrm{DA}$ in the presence of AA, confirming the significant reproducibility of the modified electrode. This result supports the ability of the PA-SWNTs/GCE-modified electrode to determine DA concentration without any interference from AA. Meanwhile, the anodic peak potentials of DA $(0.16 \mathrm{~V})$ and $\mathrm{AA}$ $(-0.07 \mathrm{~V})$ at the modified electrode were all distinguishable. The DA detection presenting as a positive charge in $0.1 \mathrm{M}$ PBS solution at $\mathrm{pH} 7.4$ was enhanced by the electron attraction between PA and DA, whereas the AA detection presenting as a negative charge was reduced by the electron repulsion between PA and AA. This effect enabled the selective and sensitive DA detemmination in the presence of AA.
Analytical applications for dopamine determination. The applicability of the modified electrode as an electrochemical sensor was tested for the deternination of DA hydrochloride injection, in the presence of AA as interfering substance. The concentration of DA hydrochloride in the injection was determined by applying a calibration plot using the procedures proposed in this paper. The DA obtained from voltammetric method results in the injections $(\mathrm{n}=5)$ were as follows: $1.00 \mu \mathrm{M}$ DA (labeled) in the presence of I mM AA, $1.01 \mu \mathrm{M} \mathrm{DA}$ (found), $2.2 \% \mathrm{RSD}$.

\section{Conclusions}

The PA-SWNTs/GCE-modified electrode is a useful and effective sensing device for selective and sensitive DA determination in the presence of high AA concentration. The modified electrode was easily prepared in a rapid and simple procedure, and demonstrated good enhancements of sensitivity and selectivity. The combination of SWNTs as the electron transfer promoter and PA as the negatively charged binder on the electrode surface produced an efficient electrochemical sensor towards DA.

Acknowledgements. This work was supported by Research Foundation Grant funded by Chonnam National University (2006).

\section{References}

I. Jijima, S. Nattre 1991, 354,56 .

2. Wang, J.; Deo, R. P.; Poulin, P.; Mangey, M. J. Am. Chem. Soc. $2003,125,14706$.

3. Chen, R. S.; Huang, W.-H.; Tong, H.; Wang, Z.-L.; Cheng, J.-K. Anal. Chem, 2003, 75, 634l,

4. Ozoemena, K. I.; Nyokong, T.; Nkosi, D.; Chambrier, I,; Cook, M. J. Electrochim. Acta 2007, 52,4132.

5. Ma, Y.; Ali, S. R.; Dodoo, A. S.; He, H. J. Phss. Chen. B 2006, 11. 16359.

6. Zhang. P.; Wu, F.-H.; Zhao, G.C.; Wei, X.-W. Bicelectrochenistry $2005,67,109$.

7. Poh, W. C.; Loh, K. P.; Zhang, W. D.; Sudhiranjan, T.; Ye, J.-S.; Sheu, F.-S. Langmin 2004, $20,5484$.

8. Abbaspour, A.; Izadyar, A. Talanta 2007, 71, 887.

9. Song. Z.; Huang. J.-D.; Wu, B.-Y.; Shi, H.-B.; Anzai, J.-J.; Chen, Q. Sents. Actuators B 2006, 115, 626 .

10. Maleki, N,; Safavi, A.; Tajabadi, F. Anal, Chem, 2006, 78, 3820.

11. Valentini, F.; Amine, A.; Orlanducci, S.; Terranova, M. L.; Palleschi, G. Anal. Chem. $2003,75,5413$.

12. Jiao, S.; Li, M.; Wang, C.; Chen, D.; Fang. B. Electrochim. Acta 2007.52.5939.

13. Rubianes, M. D.; Rivas, G. A. Electrocheni. Commun. 2007, 9, 480 .

14. Zhang, Y.; Cai, Y,; Su, S. Anal. Biochem, 2006, 350, 285.

15. Zhao, Y.; Gao, Y.; Zhan, D.; Liu, H.; Zhao, Q.; Kou, Y.; Shao, Y.; Li, M.; Zhuang, Q.; Zhu, Z. Tatanta 2005, 66, 51 .

16. Luo, H.; Shi, Z; Li, N.; Gu, Z; Zhuang, Q. Anal. Chem. 2001, 73, 915.

17. Yogeswaran, U.; Chen, S.-M. Electrochin. Acta 2007, 52, 5985.

18. Xiang, L.; Lin, Y.; Yu, P.; Su, L.; Mao, L. Electrochin. Acta 2007 , 52,4144 .

19. Boo, H.; Jeong, R.-A.; Park, S.; Kim, K. S.; An, K. H.; Lee, Y. H.; Han, J. H.; Kim, H. C.; Chung, T. D. Anal. Chem. 2006, 78,617. 
20. Ly, S. Y. Bioelectrochemistry 2006, 68, 227.

21. Wang, H.-S.; Li, T.-H.; Jia, W.-L.; Xu, H.-Y. Biosens. Bioelectront. $2006,22,664$.

22. Liu, Y.; Zou, X.; Dong, S. Electrochem. Commm. 2006, 8, 1429.

23. Hu, C.; Chen, X.; Hu, S. J. Electroanal. Chem. 2006, 586, 77.

24. Antiochia, R.; Lavagnini, I.; Magno, F.; Valentini, F.; Palleschi, G. Electroanalysis 2004, 16, 1451 .

25. Wu, K.; Fei, J.; Hu, S. Anal. Biochem. 2003, 318, 100.

26. Wang, Z.-H.; Liang, Q.-L.; Wang, Y.-M.; Luo, G.-A. J. Electroanal. Chem. 2003, 540, 129.

27. Zou, Y.; Sun, L.; Xu, F. Talahta 2007, 72, 437.

28. Zhao, Y.-D.; Bi, Y.-H.; Zhang, W.-D.; Luo, Q.-M. Talanta 2005 , 65,489 .

29. Luque, G. L.; Ferreyra, N. F.; Rivas, G. A. Talanta 2007, 71, 1282.

30. Antiochia, R.; Gorton, L. Biosens. Bioelectron. 2007, 22, 2611.

31. Chu, X.; Duan, D.; Shen, G.; Yu, R. Talanta 2007, 71, 2040.

32. Lin, Y.; Lu, F.; Tu, Y; Ren, Z. Nano, Lett. 2004, 4, I9I.

33. Zhu, L.; Zhai, J.; Yang, R.; Tian, C.; Guo, L. Biosens. Bioelectron. $2007,22,2768$.

34. Zeng, J.; Gao, X.; Wei, W.; Zhai, X.; Yin, J.; Wu, L.; Liu, X.; Liu.
K.; Gong, S. Sens. Actuators B: Chemica/ 2007, 120, 595.

35. Zhang, M.; Gorski, W. J. Ant. Chent. Soc. 2005, J27, 2058.

36. Wu, K.; Hu, S.; Fei, J.; Bai, W. Anal. Chim. Acta 2003, 489, 215.

37. Persson, H.; Turk, M.; Nyman, M.; Sandberg, A. S. J. Agric. Food Chem, 1998, 46, 3194.

38. Crea, P.; de Robertis, A.; De Stefano, C.; Sammartano, S. Biophys. Chem. 2006, 124, 18.

39. De Stefano, C.; Milea, D.; Porcino, N.; Sammartano, S. J. Agric. Food Chem. 2006, 54, 1459.

40. De Stefano, C.; Milea, D.; Sammartano, S. Biophys. Chem. 2005, 116,111 .

41. Yang, L.; Liu, H,; Hu, N. Electrochem. Commm, 2007, 9, 1057.

42. McKenzie, K. J.; Marken, F.; Opallo, M. Bioelectrochem. 2005 , $66,41$.

43. Paddon, C. A.; Marken, F. Electrochem. Conmitm. 2004, 6, 1249.

44. Mckenzie, K. J.; Marken, F. Langmuir 2003, 19, 4327.

45. McKenzie, K. J.; Marken, F.; Hyde, M.; Compton, R. G. New J. Chem, 2002, 26, 625 .

46. Zhang. G.; Xu, J.; Chen. H. Electrochen. Conmtin. 2006, 8, 148.

47. Chamssedine, F.; Claves, D. Chem. Phys. Lett. 2007, 44, 102. 